\title{
River and Estuary Current Power Overview
}

\author{
Jorel Flambard ${ }^{1,2,3}$, Yassine Amirat ${ }^{1}$, Gilles Feld ${ }^{1}$, Mohamed Benbouzid ${ }^{2,4, *(1)}$ \\ and Nicolas Ruiz ${ }^{3}$ \\ 1 Institut de Recherche Dupuy de Lôme (UMR CNRS 6027 IRDL), ISEN Yncréa Ouest Brest, 29200 Brest, \\ France; jorel.flambard@isen-ouest.yncrea.fr (J.F.); yassine.amirat@isen-ouest.yncrea.fr (Y.A.); \\ gilles.feld@isen-ouest.yncrea.fr (G.F.) \\ 2 Institut de Recherche Dupuy de Lôme (UMR CNRS 6027 IRDL), University of Brest, 29238 Brest, France; \\ Mohamed.Benbouzid@univ-brest.fr \\ 3 GUINARD Energies, 29200 Brest, France; n.ruiz@guinard-energies.com \\ 4 College of Logistics Engineering, Shanghai Maritime University, Shanghai 201306, China \\ * Correspondence: Mohamed.Benbouzid@univ-brest.fr; Tel.: +33-2980-18007
}

Received: 3 September 2019; Accepted: 2 October 2019; Published: 12 October 2019

\begin{abstract}
This paper presents a review of the stream current power sector, with a distinction made between the marine (MCP) and the river/estuary current power (RECP). Although scientific literature about MCP is actually well defined, that about RECP seems small, though this domain has some research interest. This paper has thus a special emphasis on this latter, with comparative studies done between these domains. The assessment of the academic and industrial interests for the RECP is first addressed, based on two main scientific resources and a qualitative highlight of its potential. Then, a review of actual constraints restricting its development is introduced, followed by a non-exhaustive presentation of industrial projects. Finally, some development prospects allowing constraints to be mitigated are proposed. Globally, MCP and RECP are treated unconcernedly, with a primary interest on the mechanical converter study and the location energy potential estimation. It has been highlighted that countries with RECP potential are more plentiful, and that undertaken projects can be classified mainly into two categories following the nominal power of the production unit. Furthermore, the river current power growth has been confirmed in recent years, with a majority part of patented hydrokinetic technologies, although commercial deployments are still scarce.
\end{abstract}

Keywords: river current power; hydrokinetic turbines; energy potential; industrial projects

\section{Introduction}

In recent years, a closer look at the stream current power sector provides the observation that its development is sustained despite some difficulties. Provided by the hydrokinetic energy conversion to electricity (distinguishable from its potential energy conversion, produced by hydroelectricity dam with water retention, whose worldwide exploitation is established for a long time), this renewable energy source has the advantage of being predictable on a longer time scale than the wind energy or the photovoltaic in tidal case, and to be continuous in case of river exploitation. Its extractable global potential thus is estimated at $450 \mathrm{TWh}$ /year worldwide [1] and could exceed a $120 \mathrm{GW}$ capacity [2], without river exploitation. Yet, in 2017, with a visible growth in Table 1 and considering all marine energies, a $526 \mathrm{MW}$ installed capacity has been estimated for a 1 TWh production [3], highlighting possible sector growth. However by its nature, the exploitation of this resource can only be useful for countries close to oceans, or to a large extent, countries crossed by rivers with low drop, a high enough flow rate and a suitable bathymetry. In this regard, marine current power (MCP) exploited in oceans should be distinguished from river or estuarine current power (RECP), on which this present study 
is focused. It will also highlight the fact that by its proximity to consumers, its use for isolated site electrification or power deletion seems relevant.

Table 1. Marine electricity capacity/production worldwide [3].

\begin{tabular}{lcccccccccc}
\hline & \multicolumn{1}{c}{ Marine Energy Capacity (MW)/Marine Energy Production (GWh) } \\
\cline { 2 - 11 } Worldwide & \multicolumn{10}{c}{ Years } \\
\cline { 2 - 11 } & $\mathbf{2 0 0 8}$ & $\mathbf{2 0 0 9}$ & $\mathbf{2 0 1 0}$ & $\mathbf{2 0 1 1}$ & $\mathbf{2 0 1 2}$ & $\mathbf{2 0 1 3}$ & $\mathbf{2 0 1 4}$ & $\mathbf{2 0 1 5}$ & $\mathbf{2 0 1 6}$ & $\mathbf{2 0 1 7}$ \\
\hline Capacity & 245 & 244 & 250 & 503 & 510 & 509 & 513 & 513 & 519 & 526 \\
Production & 487 & 486 & 514 & 564 & 963 & 926 & 999 & 1008 & 1024 & \\
\hline
\end{tabular}

The RECP presents a hybrid feature because it is at the interface between hydroelectricity and tidal energy conversion, both involving water kinetic energy exploitation. It therefore includes the energy conversion from tides near coasts, which is periodic, and the continuous energy provided by the free flow of rivers, without any dam or run of river hydro system. So generally, the theoretical estimation of extractable energy in estuarine areas is not simple.

The study from a historical point of view submitted by Els and Junior [4] on the hydrokinetic exploitation to produce electricity in Brazil is applicable for others developed countries with some streams: a first developing and progressive phase, for local electrification purposes, followed by a neglect or replacement in profit of hydroelectric dams, in a primary ambition of national electric unification. Others countries tend to follow this pattern with a greater consideration of the environmental impact, thus of the renewable energy consumption. More generally, this renewable energy exploitation policy is also observable in developed countries, with a part over $25 \%$ in worldwide global electric production [5].

This paper is organized as follows: Section 2 first evaluates academic considerations on the RCEP domain, then studies the RECP worldwide operation potential, and highlights the actual industrial applications of this sector. Considering that the RECP operation potential is far from being fully used, Section 3 details the constraints that manufacturers have to face, and Section 4 provides more specific information on RECP technological advancements. Finally, Section 5 summarizes and discusses the results and observations made in this paper.

\section{River/Estuarine Current Power Report}

\subsection{Academic Interest on River and Estuarine Domain}

River kinetic energy exploitation is old [4], and it passed through different steps before being used to produce electricity. Its distinct study from the MCP is less active in terms of update and dedicated research papers. Indeed, a majority of papers with a hydrokinetic topic are focused on several hundreds $\mathrm{kW}$ production units, unsuitable in terms of dimensions and minimal water depth for a generalized river or estuarine application. Vermaak et al. [6] pointed out a lack of literature and research paper on low power stream generation applied in case of rural or isolated area, which could demonstrate the technical, economic and environment benefits of this technology compared to others rural electrification techniques, such as a diesel generator.

On the basis of research papers from the 2010-2018 period, containing the keyword 'hydrokinetic', in the specific resource IEEE Xplore and the multidisciplinary resource ScienceDirect (Elsevier), and respectively limited to the 'Conferences' and 'Journals \& Magazines' categories in the first resource and to the 'Review' and 'Research' in the second, a statistic overview has been realized.

Figure 1 shows the increasing interest in the hydrokinetic power topic, particularly observed in the last five years. The study temporal restriction of this two resources has been motivated by the low number of published papers during the previous years (Resp. from 2009 to 2005: 4, 2, 0, 2 and 1 in IEEE; 15, 14, 9, 9 and 8 in Elsevier). 
Qualitatively, Figures 2 and 3 show a prevalence of papers presented at conferences and submitted as research papers. In reality, this latter point has to be qualified because the number of state-of-the-art papers submitted as research papers is important.

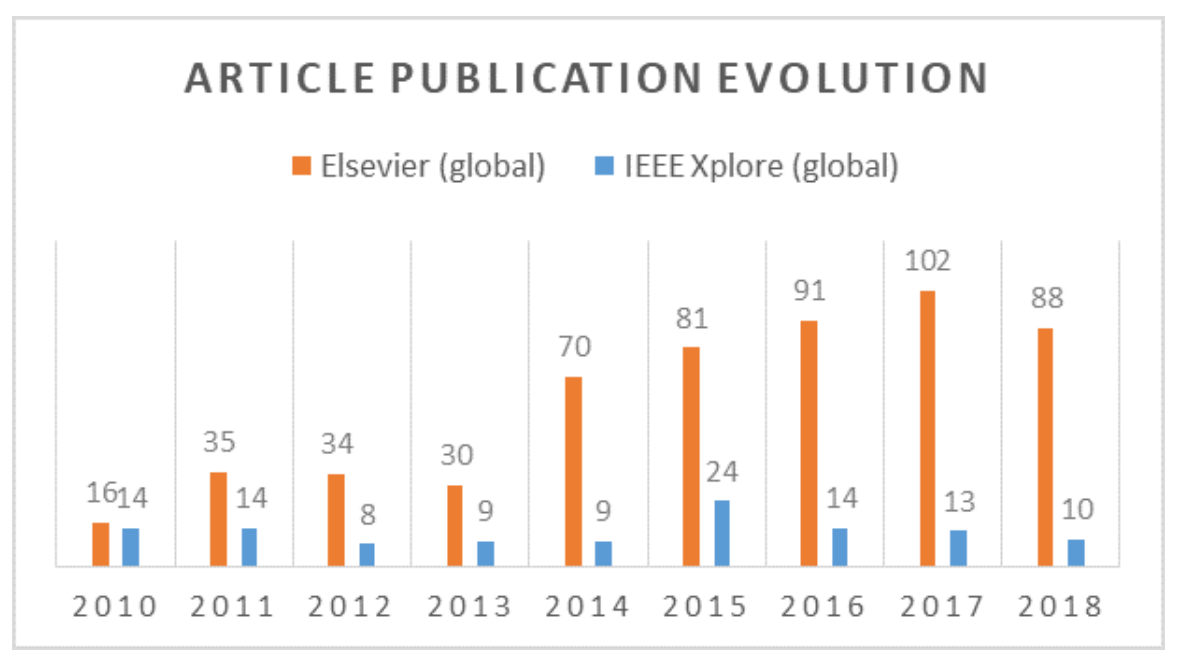

Figure 1. Evolution of paper publications containing the keyword 'hydrokinetic' on the 2010-2018 period.

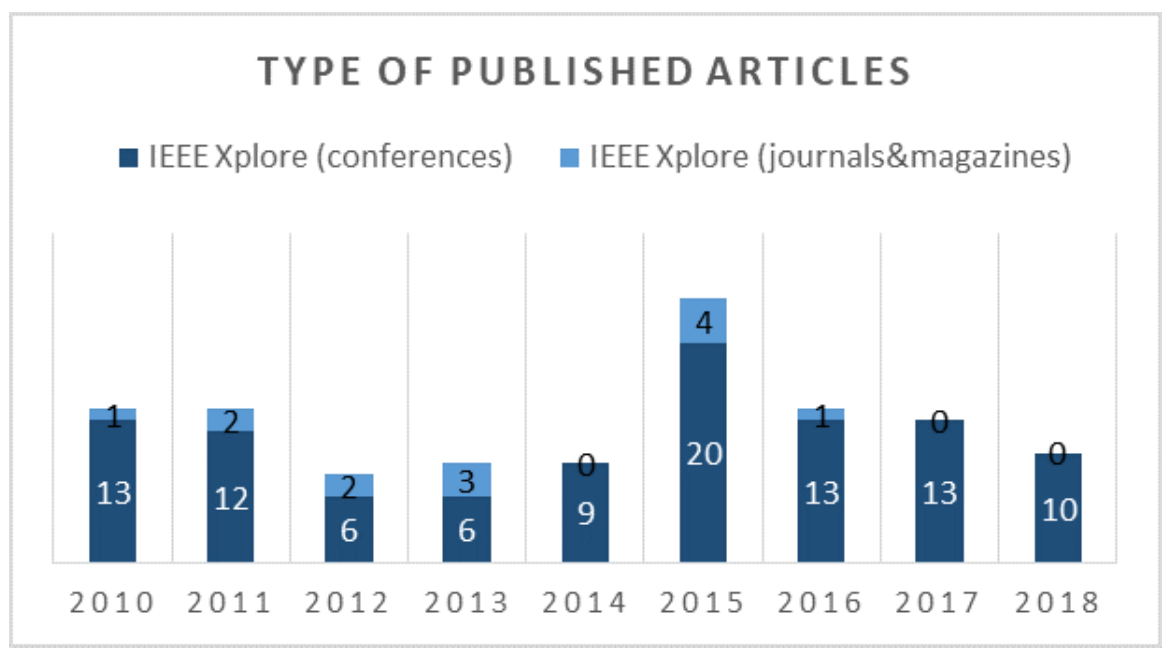

Figure 2. Type of published papers in IEEE resource.

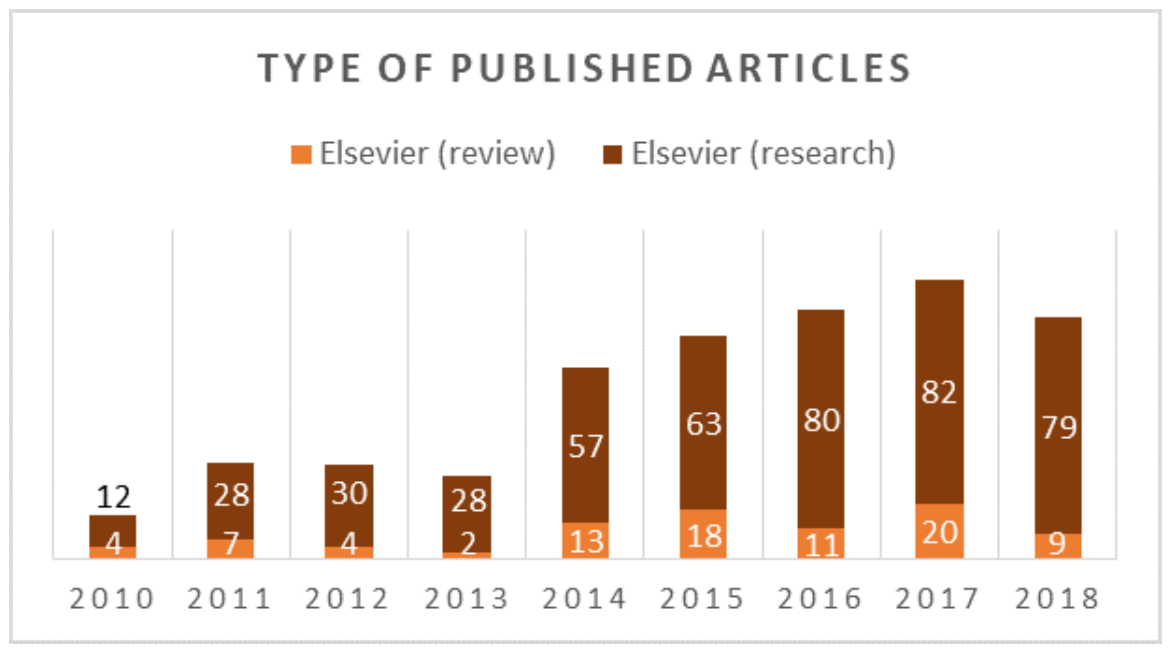

Figure 3. Type of published papers in Elsevier resource. 
The papers also have been classified according to their topics associated with hydrokinetic power:

- Mechanical (turbine modeling, flow, fluid mechanics, etc.),

- Electrical (Conversion chain, command strategy, etc.),

- General (State of the art, energy or bathymetric characterization of sites, technical-and-economic analysis, general study about hydrokinetic power, concept proof, etc.),

- Off-topic (Papers explicitly not about hydrokinetic power or irrelevant, unfinished studies, etc.).

The electromechanically oriented papers are half recorded in the 'Mechanical' and 'Electrical' categories in order to conserve a paper total number equal to that obtained in the per year breakdown.

Figure 4 shows a thematic disparity: a majority of hydrokinetic power related papers is mechanical-oriented, with numerical modelings under specific assumptions and boundary conditions. This trend is justifiable by the need for accurately modeling the turbine behavior under turbulent flows, in order to estimate as closely as possible their performance. In that respect, different models have been developed for various configurations, such as in free flow, operation with nozzle, and the study of turbine wake features in an environment. Silva et al. [7] notably underline the specific case of studies in rivers where the depth and width of waterways are constraining parameters to consider. It can be noticed that a minority part of papers considers mechanical converters other than turbine, such as oscillating or vibrating converters. The electromechanical or energy conversion orientation is sparsely represented in these resources, but this remark only concerns papers combining this aspect with the keyword 'hydrokinetic'. The research papers dealing with electrical energy conversion related to hydrokinetic power are thus still under-represented.

\section{Topics distribution (\%)}

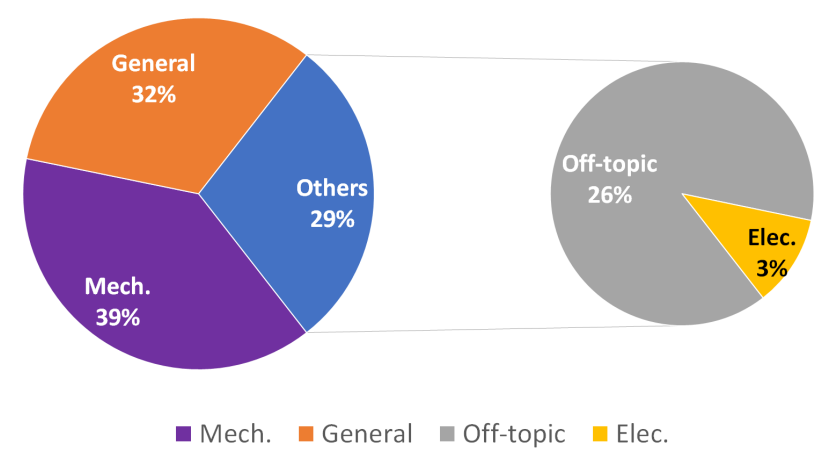

Figure 4. Paper distribution per thematic.

The papers classified in the 'General' category convey a prospect publication trend in the stream current power sector, the exploitation of ocean energy or more broadly renewable energies, and studies on usable energy potential for specific locations. Yuce and Muratoglu [8] is notably appreciable for its global review of hydrokinetic energy conversion systems, categorized in two main groups based on the converted energy nature, from waves or water current. Their technologies, operation principles, environment impacts, energetic potential, benefits, drawbacks and associated issues are detailed.

From a project-based approach, Segura et al. [9] presented a multidisciplinary analysis named PESTEL (political, economical, social, technological, environmental and legal), and an updated state of the art on the MCP sector in the European Union. From the perspective of the RECP, its validity becomes partial, even though adaptable: consensus formation among stakeholders (such as river manager, fishery operator, or user for recreation) is necessary to implement the river and estuary current power overview. Adding knowledge about the consensus building process would be a plus to help trying to implement these technologies.

The significant part of 'Off-topic' papers should also be noticed in Table 2, of which the thematic distribution on the 2010-2018 period is given in more detail. The bigger part in the Elsevier resource, 
regardless of the published paper number and associated with the keyword, can be explained by the multidisciplinary nature of this resource. It highlights too a lack of relevance in the combination of keyword with papers, some of them only including the term 'hydrokinetic' once, such as Yan et al. [10], which is a paper about horizontal drilling.

Table 2. Details on paper thematic distribution.

\begin{tabular}{lcc}
\hline Topic Types & No. Papers & No. (\%) \\
\hline Elsevier (Mech) & 211.5 & 31.95 \\
Elsevier (Elec) & 5.5 & 0.83 \\
Elsevier (General) & 172 & 25.98 \\
Elsevier (Off-topic) & $\mathbf{1 5 8}$ & $\mathbf{2 3 . 8 7}$ \\
IEEE Xplore (Mech) & 45 & 6.80 \\
IEEE Xplore (Elec) & 16 & 2.42 \\
IEEE Xplore (General) & 42 & 6.34 \\
IEEE Xplore (Off-topic) & $\mathbf{1 2}$ & $\mathbf{1 . 8 1}$ \\
\hline
\end{tabular}

Finally, the papers have been classified by country according to the geographical origin of associated laboratories. For the sake of readability, the classification has been generalized at a continental scale, and the papers previously categorized as being 'Off-Topics' have been ignored.

Figure 5 shows that research activities in stream current power domain comes in the majority from the North American continent, particularly in the IEEE resource. This trend is significantly due to an important number of IEEE conferences on North American soil. Asia globally comes in second position with China leading, followed by India and Malaysia. In Europe, the United Kingdom (UK) is logically the leader, since its coasts possess most of the MCP operation locations, followed by France and Italy. On the African continent, South Africa records practically the entirety of publications; in South America, it is Brazil, and Oceania is the less represented in terms of paper. For the latter, this statement can be explained by the narrow referencing of papers written in Spanish or Portuguese language and by the energy strategic of Australia, most populated country in Oceania, of which the electricity produced is mainly thermal generation, although a current power exploitation potential has been identified near its north coast in Hemer et al. [11]. The 'Global' category regroups the papers coming from collaborations between several laboratories of different countries.

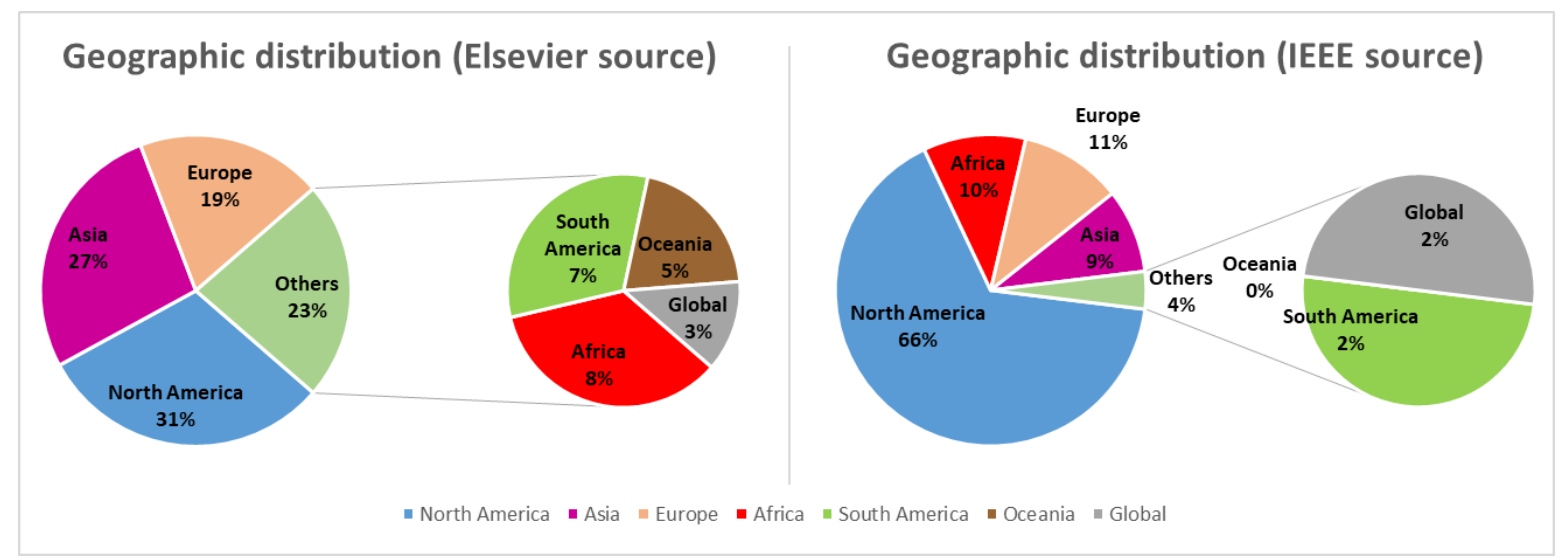

Figure 5. Paper geographic distribution, by continent.

The academic regard emerging from this analysis points out a primary interest of mechanical converter study (turbine, hydrofoil, etc.) and the energy potential estimation of location, what is relevant as these two points are the basis of any electromechanical conversion chain in hydrokinetic power. The electromechanical conversion and command study should not be neglected, because the final electric production is just as reliant on it. Furthermore, among the papers that introduce 
an experimental performance, most of them can still be considered as proof-of-concept because the results or obtained data remain incomplete and short in terms of time. The publication of papers using long-term measurement campaigns from 'industrial' equipments (real installation location, turbine and conversion chain at full scale) thus represents an obvious interest for scientific community.

As a whole, this bibliographic study does not point to a firm distinction between hydrokinetic high power and low power, logically better suitable for rivers or estuarine location. Apart from a few papers that introduce a studied environment, a geographic location of interest or a nominal power of the considered hydrokinetic device, only an in-depth analysis of study parameters or simulation provide an identification of the considered hydrokinetic power operation location. So, the theoretical hydrokinetic power generation from these environments should be studied and identified worldwide.

\subsection{Strong Operation Potential by Its Consumer Proximity}

At first sight, the RECP development seems more modest than the MCP in terms of extractable power, but it is compensated for by a greater production capacity at local scale. As outlined by [4], the development and retrofit of countries implies an increasing consumption of electricity and the establishment of an electrification policy. For this reason, hydrokinetic power operation can be interesting to countries in which an energy potential has been recognized and of which its electrical coverage is unequal.

In a first global approach, statistic data from the international energy agency (IEA) [12] formatting, Figures 6 and 7, highlight world regions where the population does not have access to electricity. The regions of sub-Saharan and south-east Asia are the most exposed, the first is characterized by an important part of its rural population without electricity access Figure 6, and the second by a high population density Figure 7, despite a high electrification rate. Haiti case should be noticed too, in the Caribbean, with a poor national electrification rate of $30 \%$.

On these maps can be superposed Figure 8, a NASA map, which illustrates the world region where the tidal energy dissipation is important, thus some areas of interest close to shore for MCP operation:

- Marine area limited by Indonesia, Papua New Guinea and the north of Australia;

- $\quad$ East coast of China;

- $\quad$ East coast of Alaska;

- The Hudson's bay (Canada);

- Marine area located near the southern tip of Argentina;

- Marine area restricted by UK, republic of Ireland and France.

Proportion of rural population with access to electricity, 2017

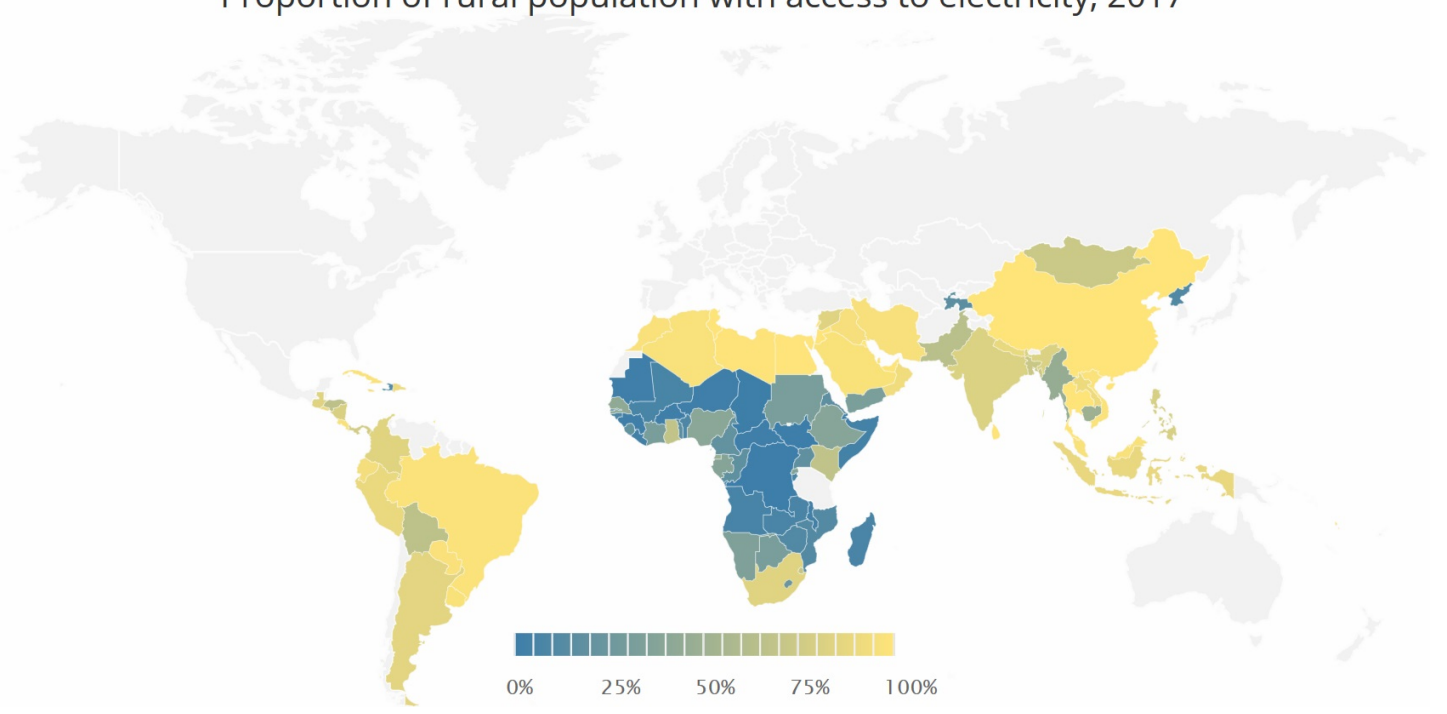

Figure 6. Proportion of rural population with access to electricity, 2017 [12]. Source: Reproduced with permission from IEA (2017) Sustainable Development Goal 7, 2017. 


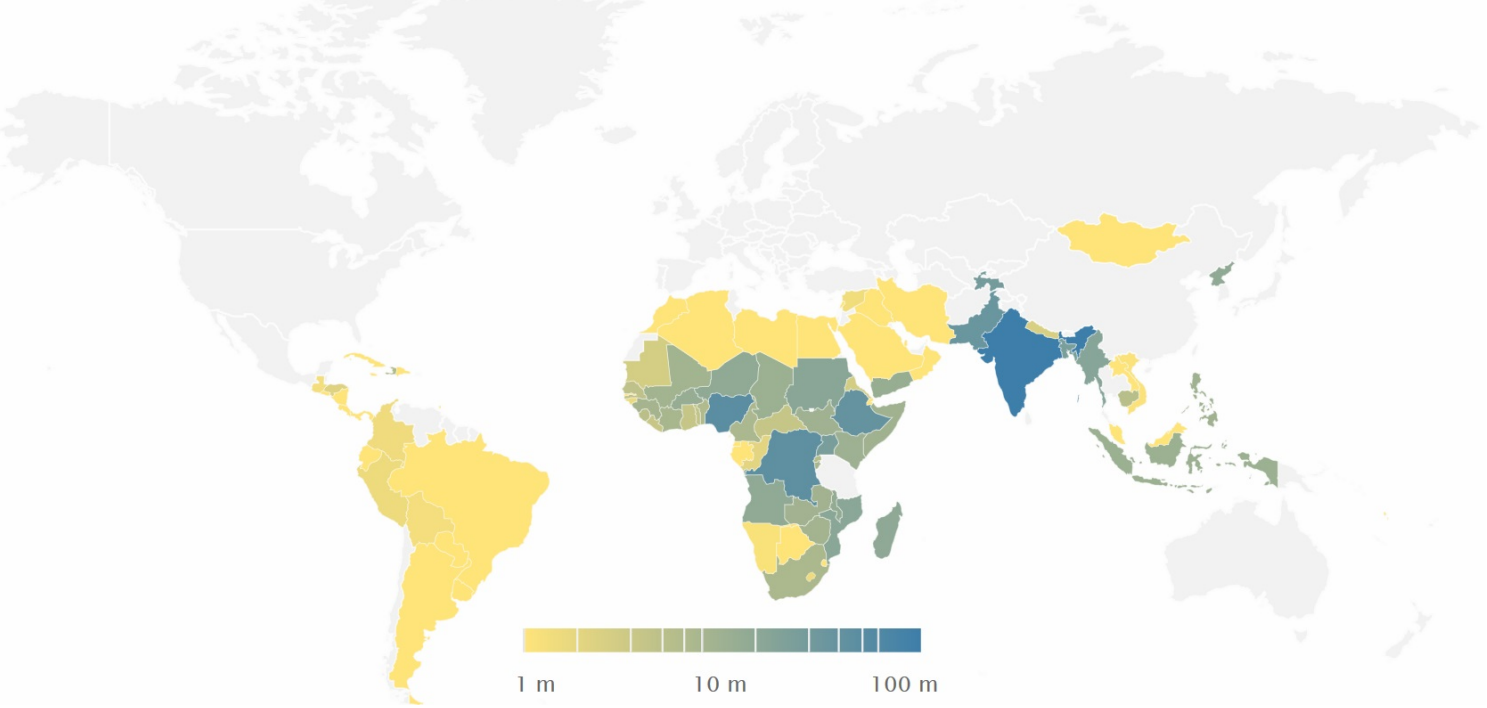

Figure 7. Population without access to electricity, 2017 [12]. Source: Reproduced with permission from IEA (2017) Sustainable Development Goal 7, 2017.

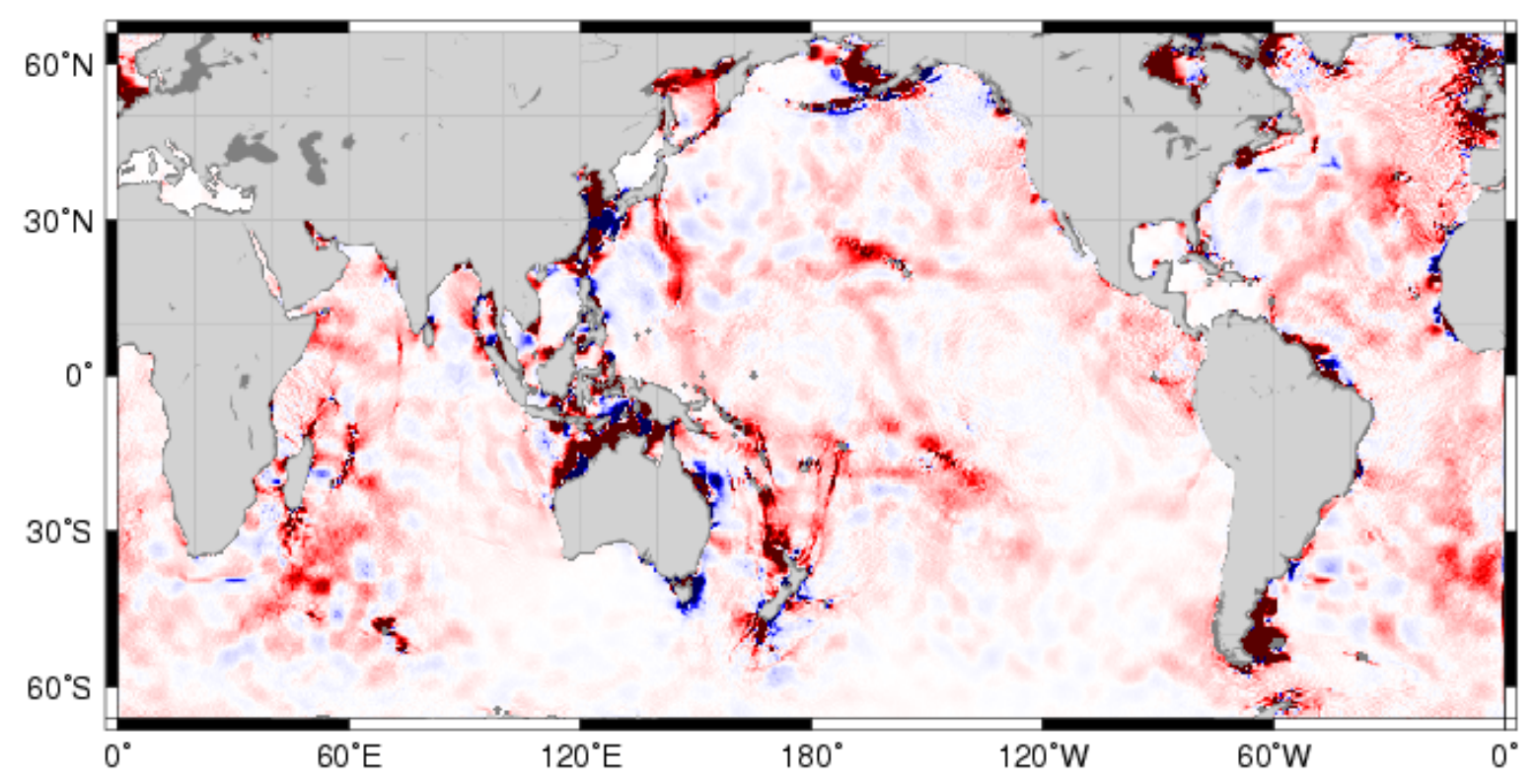

R Ray, GSFC

Figure 8. Tidal energy dissipation, the red areas are the most energetic [13]. C Reproduced with permission from NASA - Goddard Space Flight Center, NASA - Jet Propulsion Laboratory and Scientific Visualization Studio, 2019.

Several coastal areas with a lesser area are also identifiable, such as those around Madagascar or close to French Guyana shores and Brazil. In this way, the cross referencing from Figures 6-8 allows identifying an operation interest in the south-east Asia region and the south-east sub-Saharan coast.

This approach can be used as a baseline study, but it totally omits the RECP operation potential, which does not exclusively concern the countries bordered by a sea or an ocean. The European example illustrates well this matter, from distribution map of MCP and run-of-water resource, Figure 9: if the marine operation locations are mainly identified near the UK, the countries with a river operation potential are more plentiful. 


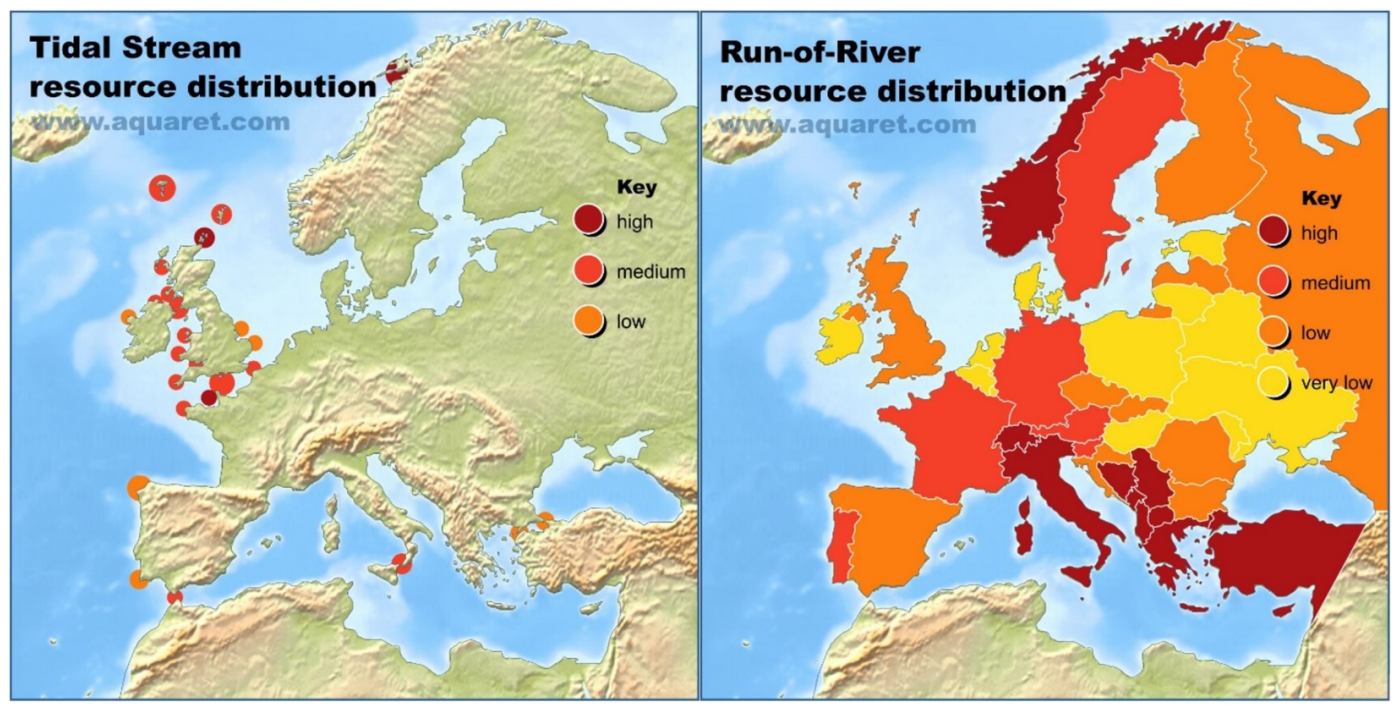

Figure 9. Distribution maps of tidal stream and run-of-river resources (based on rainfalls and river drop) [14]. (C)Reproduced with permission from Aqua-RET Project, 2019.

This case is not specific to Europe and is also observable in others world regions such as the Gulf of Guinea, yet identified as low in energy according to Figure 8. Thus, in Nigeria, the techno-economic analysis carried out by Amoo [15] about energy production for river or estuarine locations, by resource characterization from unequally allocated data over time by means of the wavelet transform, foreshadows a production potential for several locations split in the country. However, as mentioned before, the particularization of the RECP is impossible because the hydraulic power production is mostly considered. Yet, the hydrokinetic production potential could be approximated by micro-hydro production $(20$ to $500 \mathrm{~kW})$ or run-of-water pico-stations $(<20 \mathrm{~kW})$ in view of their application in some rivers with a difference in the height levels of water almost null, as explained in Wagner et al. [16], but more generally in terms of production data, the production from these type of power station is not always itself defined explicitly.

\subsection{Industrial Consideration on Stream Current Power Domain}

From an industrial point of view, many researchers, including Chen et al. [17], studied the related issues of marine energy conversion, and they listed some pilot projects undertaken around the world. Moreover, a report from a European committee [18] about the non-exhaustive identification of emerging future technologies in the marine energy sector was submitted. A classification based on hydrokinetic technology generation was proposed:

- First generation: Conception similar to onshore wind turbine, technologies using a horizontal axis turbine or a nozzle turbine which is stationary referred to the seabed.

- Second generation: Technologies which turbine is not stationary, using a floating or partially submerged platform on which one or several turbines are fixed.

- Third generation: Technologies not using turbine as mechanical converter.

Generally, these pilot projects can be distinguished as being either high power production projects (MW) based on second or first generation technologies, or smaller projects using second and third generation technologies and/or whose main goal is to increase reliability and to validate the proposed technological choice, in particular with small scale prototypes. In these two categories, many developments are still under investigation and the interested reader will find more information in the two previous references and on the involved manufacturer websites. Inevitably, a few projects placed in safe mode or dropped out occurred, notably the NavalGroup investment waiver and the OpenHydro company liquidation which impacted the hydrokinetic sector growth in France. 
However its development carries on in Europe, a UK leadership trend is thus observable for high power production project.

For this reason, in recent years, the large project development focus seems to have a high power generation goal (in the scale of MW) in order to improve the energy mix at regional or national scale, through the development of important production unit. This choice induces a greater visibility, but necessarily constraining projects: development of large size turbine and alternator, significant cost, project viability politically and socially questionable, competitions against $\mathrm{PV}$ and wind turbine projects. The acknowledged environmental impact awareness of tidal array (and large hydrokinetic turbine in a lesser degree) is also crucial during these project lifetime [9]. On the other side, the projects related to modest and/or innovative production unit tend to ensure an isolated location electrification or improve the energy deletion of areas or villages, this last problematic being more and more regarded with the willingness to develop smart grid.

Concerning the operation environment, the high power generation projects are mostly MCP oriented because of their proposed production units dimensions, which cannot be installed in rivers or estuaries. On the contrary, the second categorized projects, when they are not originally designed to river/estuarine operations, have more suitable dimensions for these environments, promoting for instance in the case of isolated location electrification, a closer proximity with consumers. Furthermore, as mentioned in the report by [18], the actual technology development without traditional turbine should allow operations in rivers and areas with lesser energy assessment and so increase the hydrokinetic technology market once they will become commercially viable.

A market study ordered by SEENEOH (national estuarine experimental site of hydrokinetic device optimization and test) was realized by Energie de la Lune and a public partial synthesis is available on the project website [19]. The market sectors, Figure 10, show the number of patented hydrokinetic technologies by country and illustrate the observation previously made with a majority development of RECP worldwide, followed by the development of systems which can work as well in rivers as in ocean.

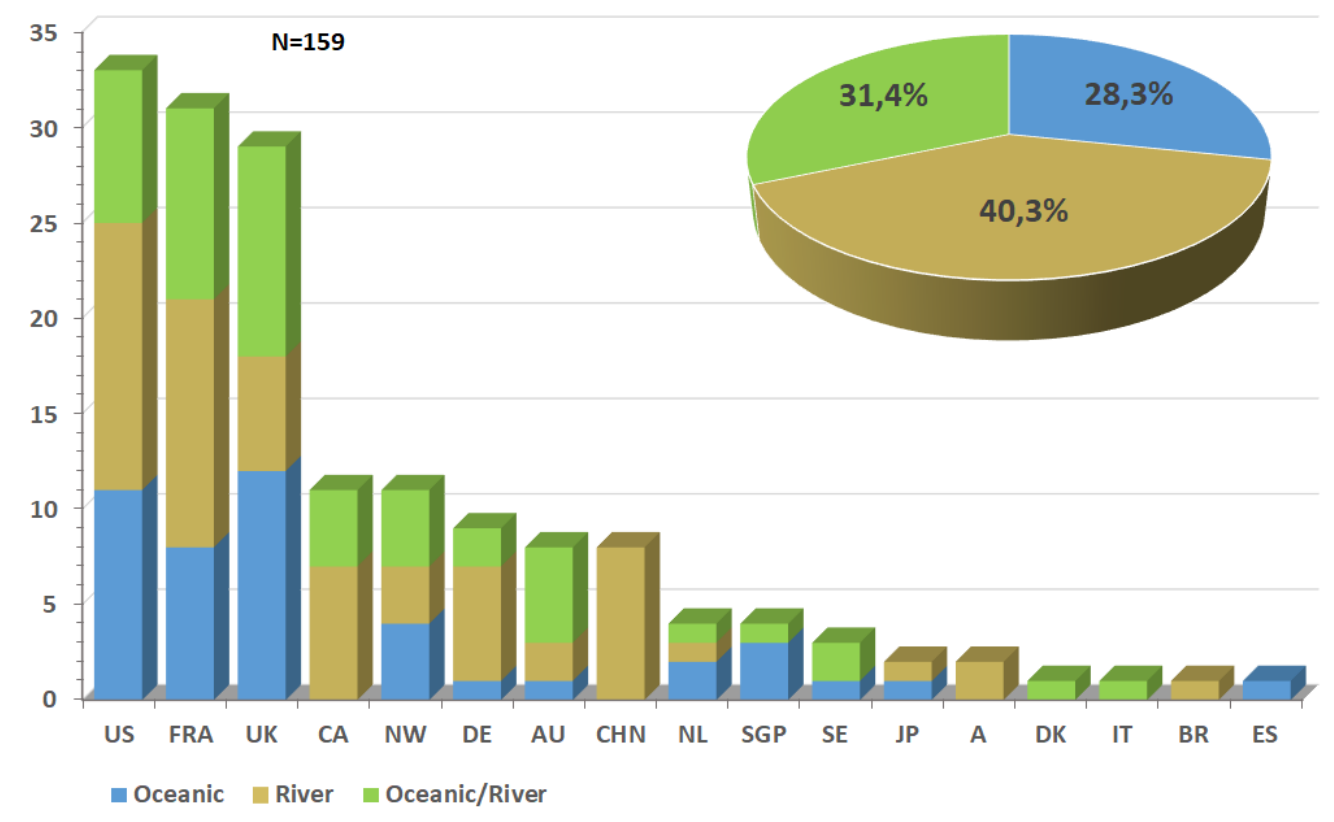

Figure 10. Hydrokinetic market sector [19]. (C) Reproduced with permission from SEENEOH, 2017.

\section{RECP Deployment Limitations}

The previous sections highlighted the interest of the RECP development, however this one, just like MCP, is slowed down by some limitations, which should be described. 


\subsection{Real Operation Potential, Under Constraints}

The RECP sector has not reached a global technological maturity yet due to the technological diversity proposed by the various manufacturers. The public results provided by SEENEOH, of which Figure 11, represents the existing variety in the turbine design and show that the proliferation of considered technologies, although axial flux turbines are still mainstream.
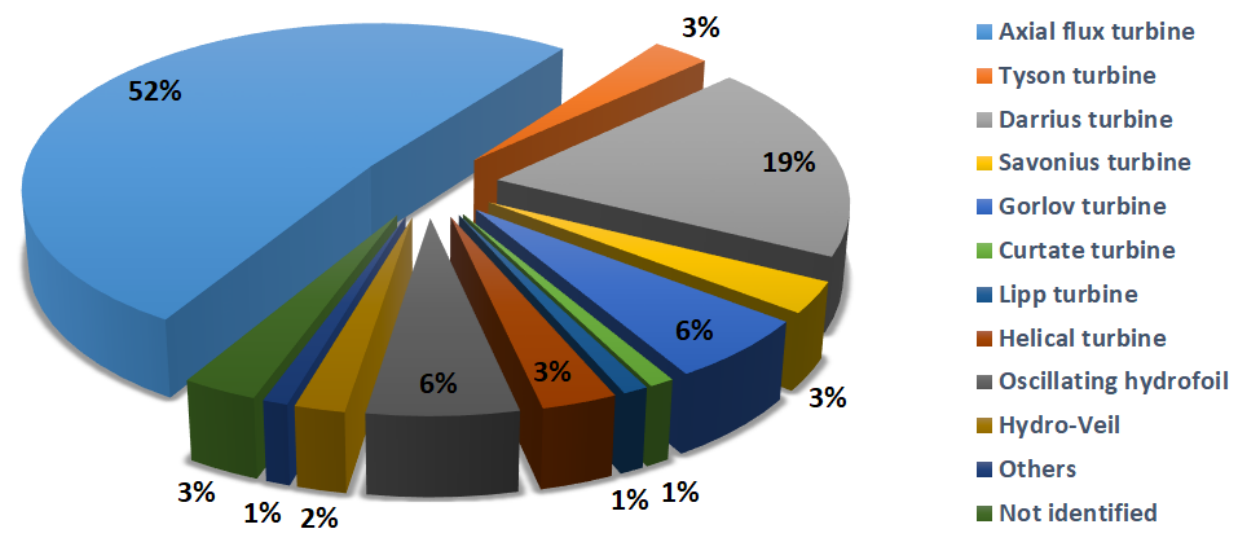

Figure 11. Turbine design, worldwide trend [19]. (C) Reproduced with permission from SEENEOH, 2017.

The proportion of mounting system, Figure 12 is related to the hydrokinetic generations, with a majority of gravity baseplate, followed by the float use, privileged in the second generation.

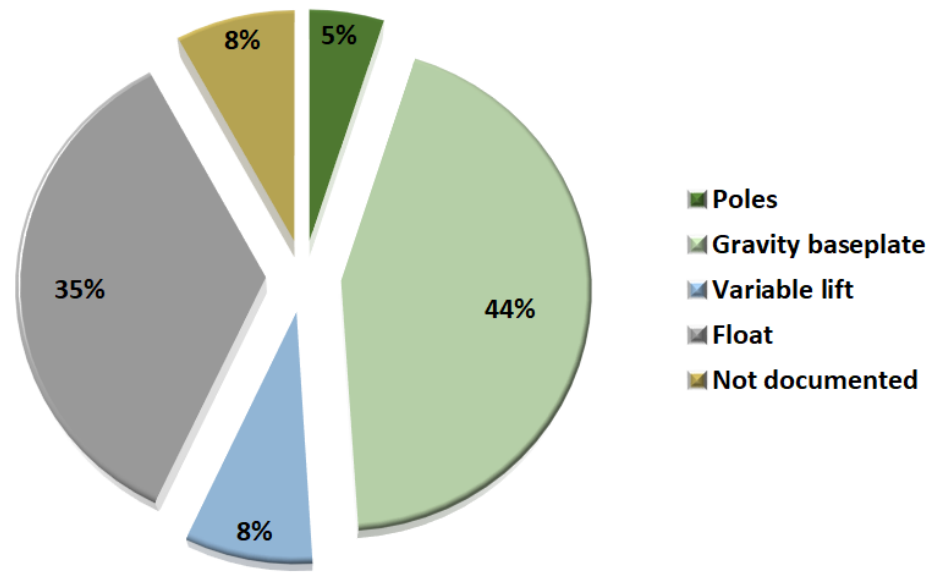

Figure 12. Type of hydrokinetic mounting, worldwide trend [19]. (C)Reproduced with permission from SEENEOH, 2017.

The hydrokinetic energy is a scattered resource which is widely available in regions with moderate water flow speed, but whose technically usable potential is affected by poor visibility. A study similar to that made by Brooks [20] in estuary areas could provide a theoretical extractable power estimation of site of interest. In practice, the already existing human activities like marine navigation, fishing zone, leisure activity, nature reserve or protected area to name but a few, involve that only a part this theoretical power could be extracted.

In this way, like its marine counterpart, the river/estuarine energy potential imply case-by-case accurate specification of hydrokinetic installation locations, and the measurement campaigns are not always public. El Tawil et al. [21] introduced a method for location energy characterization for hydrokinetic device, and underline the possibility of current asymmetrical direction close to shore, caused by the bathymetry. The use of a multidirectional hydrokinetic system in this case is justified. In addition, the lack of real or potential electrical consumption data of isolated site is a hindrance to 
energy requirement estimation, necessary for correctly sizing the electrical generation unit in order to ensure a balance between production and consumption.

Including in the off-grid case, or when a specific power profile to be supplied on grid is needed, the balance between production and consumption needs electricity storage solutions. Murray et al. [22] emphasized and compared sizing criteria and storage technology choice, in the stream current power domain. Considering factors like security, cost and complexity, it seems that lead battery solution is the more suitable than lithium-ion technology for hydrokinetic device prototyping phase. For purposes of optimized power integration on electric grid, Ben Elghali et al. [23] presented a simplified sizing method for an energy storage system, integrating an energy management strategy. This method allows the selection of adequate storage technologies and determines the required low-cost storage capacity by taking account of their limits related to the different power dynamics involved. The proposed method, independent of power level, could be use in case of RECP operation, even for a RECP cluster.

Moreover, a generalized development will be impacted by the debris constraint (wooded or not, exceptional or cyclic) which especially concerns rivers and estuary, even though observable in every environments. The Amazon River exemplifies well this statement: having the bigger watershed among all of the rivers, it carts an important amounts of organic debris from the Amazon forest. Thus with a study on wooded natural debris in rivers, Tyler [24] detailed their origins and consequences on human equipments. The bank erosion is the main cause of debris presence in a river stream, and even if most of them float in surface, some are more imposing and can move under water. Several mitigation techniques by capture or avoidance were presented, such as the use of anti-debris barrier, deflector, or anti-debris grid. However, none of these solutions is perfect because they can locally impact the water speed or create turbulence in the flow. This debris constraint, in particular when it is periodic, needs be considered throughout the choice of an installation location and a mitigation method.

The environmental constraints specific to hydrokinetic device have also to be considered in the sector development. The long-term deployment (several months) of full scale prototypes and the associated environmental report are still sparse, but numerous laboratory studies have been achieved. In particular, Nash and Phoenix [25] presented a scientific literature review on the understanding of environmental impacts caused by the kinetic energy extraction. A distinction between hydrodynamic impacts (turbulence in water flow, current speed modification, change of water turnover time near the mouth of the river) and those that are geo-biochemical (sediment transport, water quality) was done. If the considered impacts for a hydrokinetic turbine (or a cluster with a low number) seem negligible, a particular attention should be paid to case of consequent hydrokinetic turbine cluster, including to their disposal for optimizing their power generation and limiting their impact. In addition, an another biologic impact, the bio-fouling and its consequences on hydrokinetic converter is not controlled yet, and special attention is given to the toxicity of coatings and anti-fouling paints used, as seen in Figure 13. After a structure immersion for several months, a macromolecular film has partially developed. 


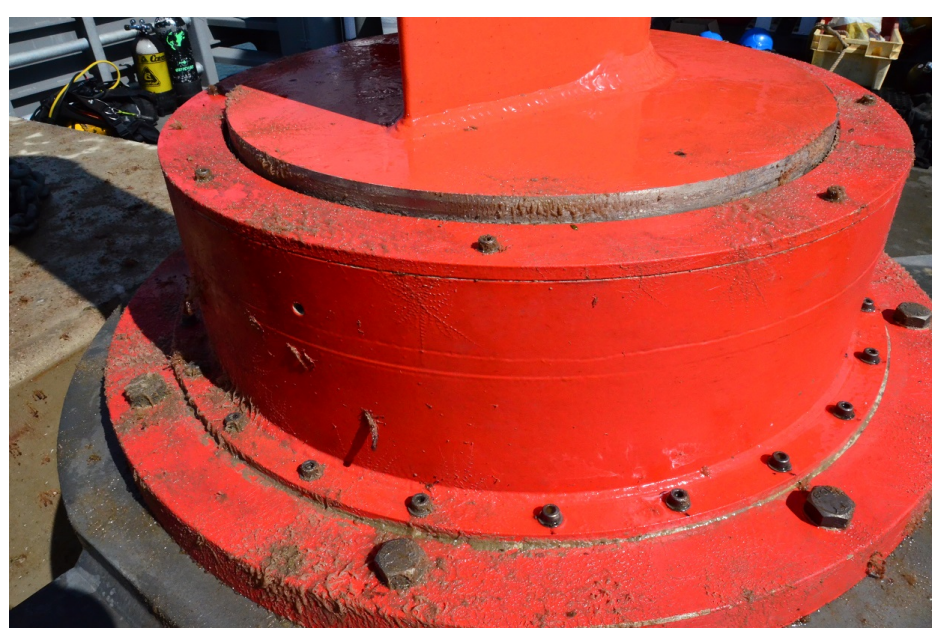

Figure 13. Biofouling formation. (C) Guinard Energies Nicolas RUIZ.

Titah-Benbouzid [26] studied this issue in the generalized context of marine renewable energy converters, highlighting the bio-fouling impact and solutions to prevent it, but the analysis of this phenomenon is complex because the bio-fouling development is a slow process, as illustrated in Figure 14.

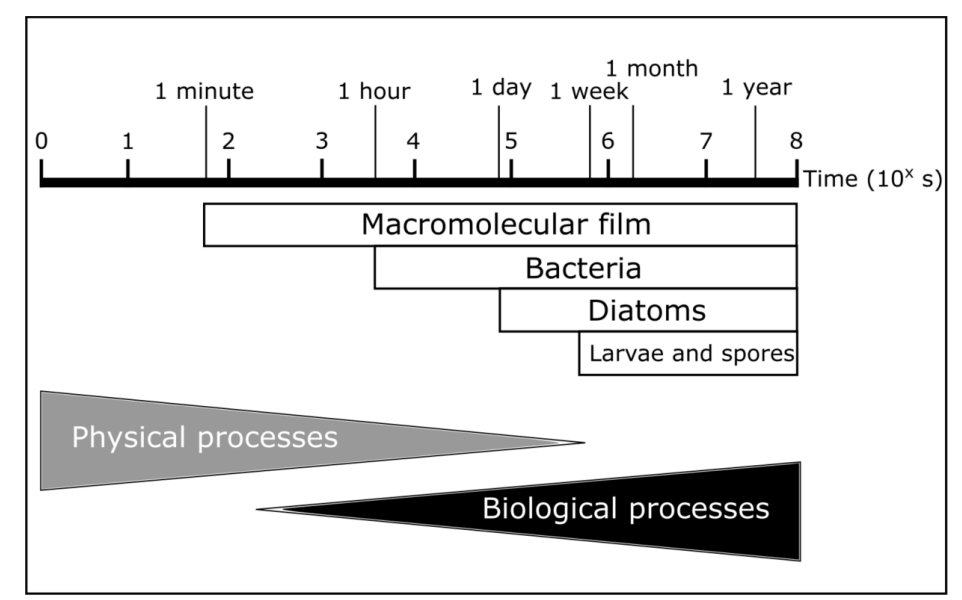

Figure 14. Schematic colonization process leading to establishment of a fouling whole [26]. (C) Reproduced with permission from European Wave and Tidal Energy Conference, 2015.

On this last point, the RECP sector differs from MCP in terms of its reduced dimensions (and so immersed surfaces) and an operation in less salty water if ever (rivers), the bio-fouling phenomenon being less severe in a freshwater environment. However, it means that hydrokinetic devices developed for river uses will require modifications in order to be fully used over time in estuarine or marine environment.

Finally from an economic point of view, many factors impact the future commercialization of hydrokinetic converter technologies [9]. Among these factors can be cited: a high level cost of stream current power $\left(\mathrm{LCOE}^{1}\right)$ compared to the others energy technology, Figure 15, considering its innovative aspect, a hard prediction of the long-term cost reduction, investment difficulties and a lack of accessible information to the public.

1 The LCOE is defined as the life-cycle cost divided by lifetime energy production. It is a convenient tool with which to compare the unit cost of different technologies throughout their economic life and serves as a benchmarking or ranking tool with which to compare different technological alternatives that could be achieved by different investments and time operations. 
Some recommendations are also suggested: Increase the capital support granted to technologies, put a reasonable price for the $\mathrm{kWh} / \mathrm{MWh}$ produced, promote the niche market such as the isolated sites, quantify the additional benefits from the hydrokinetic power energy development (environment, created employment, etc.), establish road-maps in order to reduce the LCOE of technologies, improve information access, reduce the energy project insurance costs, more guaranteed credits and more certifications and standards for equipments. Thus from this economic perspective, it can be noticed again that the RECP sector development, by its smaller investments, seems more sustainable than MCP.

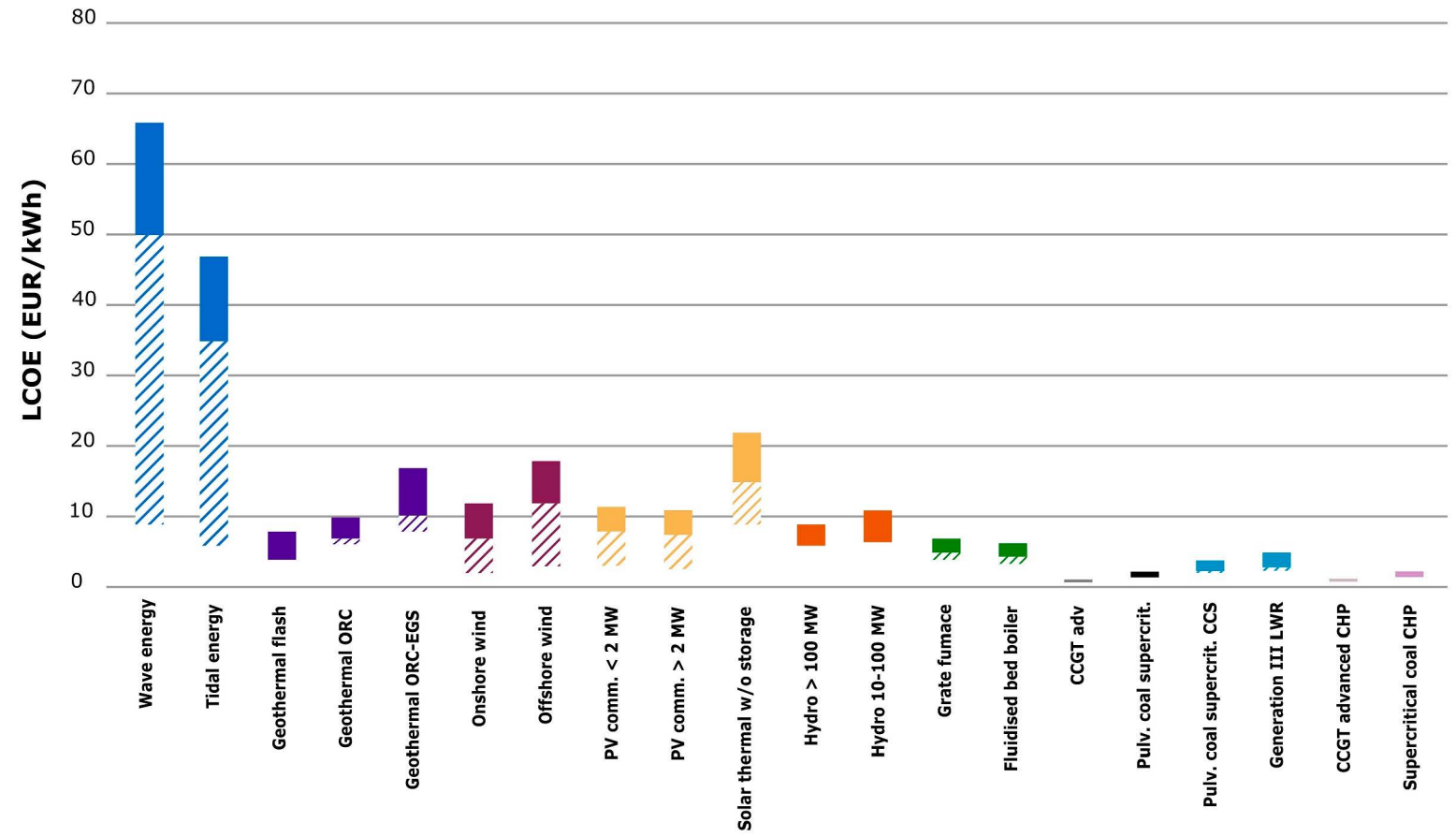

Figure 15. LCOE for different energy technologies [9]. The solid bars indicate the actual LCOE span and the striped ones, the future cost reductions expected. (C)Reproduced with permission from Elsevier, 2018.

\subsection{RECP Projects Under Development}

On the basis of information research on manufacturer website who develops hydrokinetic power systems for a river/estuarine environment, a non-exhaustive synthesis indicating the geographic location, the creation date, the type of device developed, the number of ongoing projects ${ }^{2}$ and the power product range is presented in Table 3.

It can be noticed that most of these companies are small and medium sized enterprises (SMEs), indeed the big energy corporations have little interest in this domain given that its unity production capacity smaller. Among the cited companies, a few seem to have achieved a commercial phase for a hydrokinetic device production unit. From a technical point of view, the turbine technological multitude is clearly observable, it should be noticed that only a company offers a multidirectional structure, thus enabling a better energy extraction in areas with tidal stream asymmetry and for estuaries, which are simultaneously influenced by the flow of rivers and tides. In terms of power rating, the proposed hydrokinetic systems are not exceeding $80 \mathrm{~kW}$, the higher power rating suggested by manufacturers being obtained with systems which make use of several turbines and generators.

2 N.I: Not clearly Indicated on the manufacturer website. 
Table 3. Compagnies developing river stream current devices.

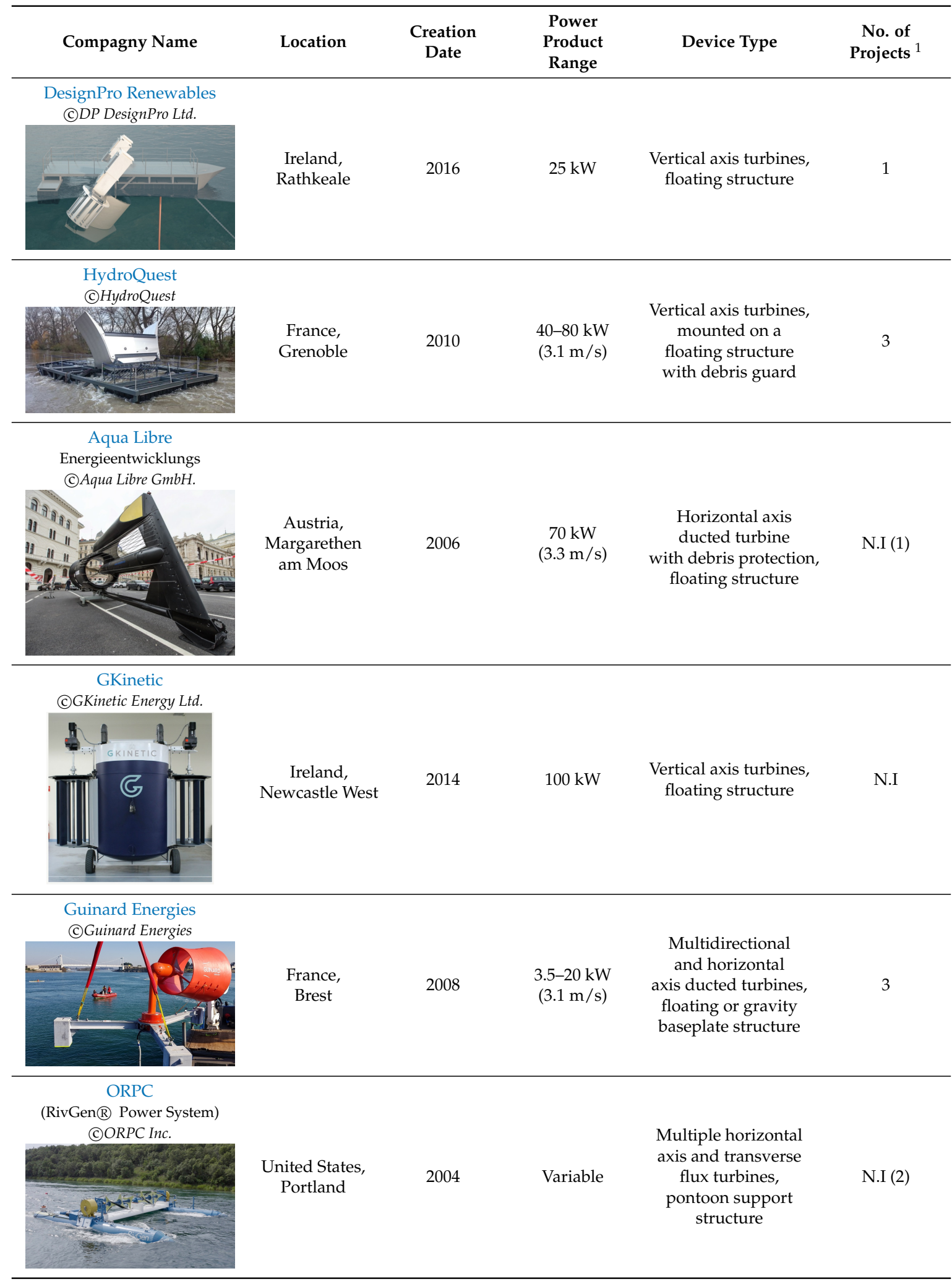


Table 3. Cont.

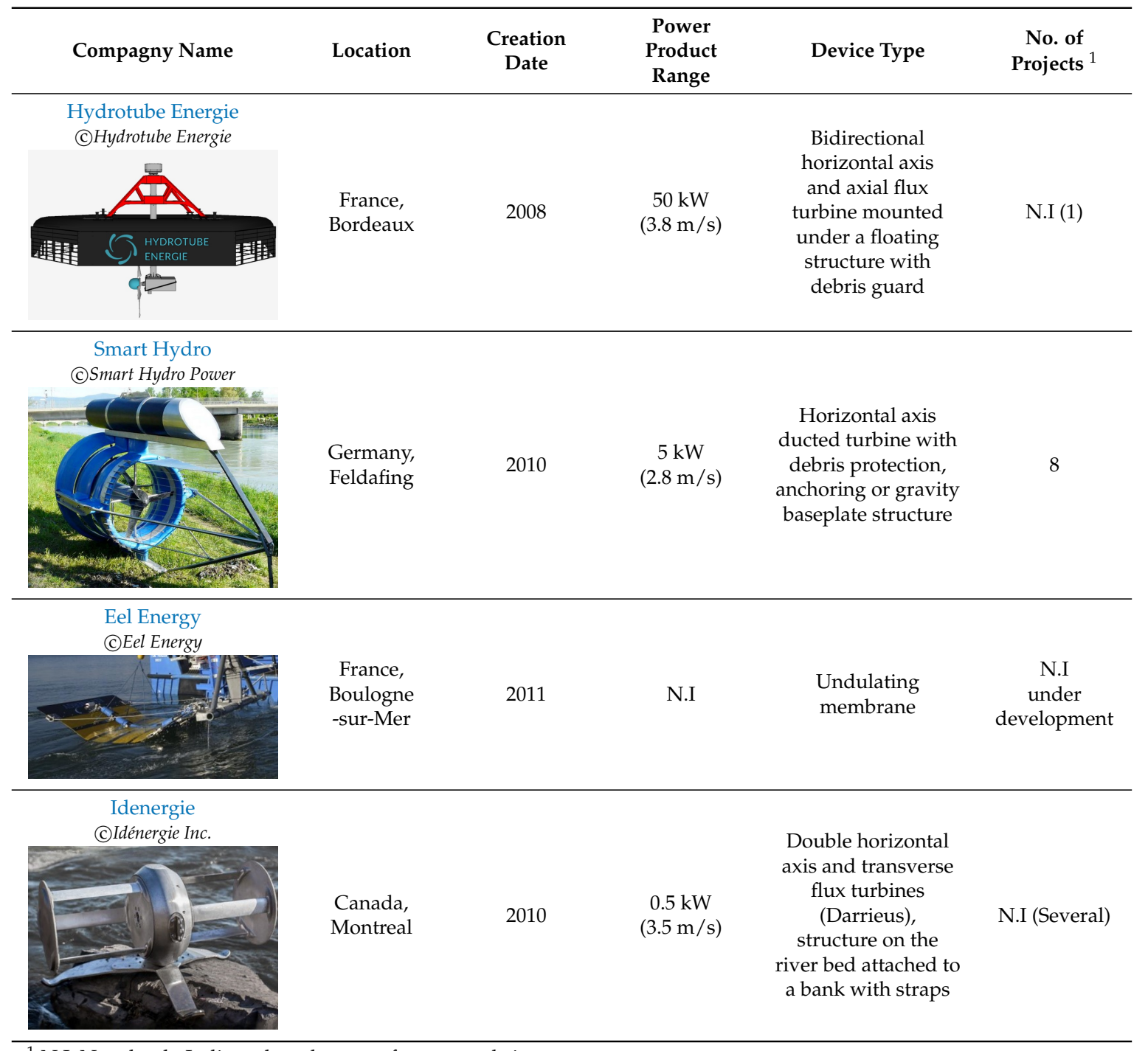

${ }^{1}$ N.I: Not clearly Indicated on the manufacturer website.

\section{RECP Technological Development Prospects}

The previous sections described some technical, social, environmental and economical constraints, as well as a few recommendations in order to ease them. In terms of technological advancement for the stream current power sector, the resource mapping improvement, the reinforcement of $R \& D$, innovation and demonstrations, the reliability enhancement, the component normalization, some industrial cooperation programs for transfer of knowledge and for serial production, and finally promoting access of test centers are as many relevant leads [9]. The development of hybrid system ensuring an electricity production complementarity by exploitation of several renewable energies remains attractive. Particularly in case of isolated sites, the energy combination potential to reduce the output power fluctuation of the ensemble, to lower the capacity storage and the diesel generator use has been demonstrated. Globally, the development of a synergy between renewable energy production and association with others activity sectors (aquaculture, transport, desalination, gas, etc.) seems also promising.

Roy et al. [27] proposed an up-to-date review of hybrid system projects based on marine renewable energies. From an industrial point of view, these systems operate above all with PV and wind turbine because these technologies are more mature, but by considering the number of projects stayed in a concept phase, their development remains premature. Several projects are closed to operational 
tests at full scale (MW), others have achieved the testing phase in sea at reduced scale. It should also be noted that a few manufacturers propose hybrid solutions, combining stream current power and photovoltaic electricity production. From an academic point of view, Tekobon [28] carried out research studies on a hybrid system offshore wind / stream current power which are based on real time simulations with hardware in the Loop (HIL) and a hydrokinetic low-power emulator (under $5 \mathrm{~kW}$ ). Of course, the integration of such energy systems in micro-grid needs specific management strategies. Zia et al. [29] present a critical and comparative analysis of decision making approach and their solving method for energy management systems (EMS). Various incertitude quantification method are summarized in order to handle the volatility and intermittency of renewable energy resources and consumption demands. A comparative analysis of communication technology is also discussed for a cost-effective installation of a micro-grid EMS, whose architecture is detailed. It is also highlighted that there is not a method better than the others, they are all worth something according to constraints and defined goals for the global management of the system.

In parallel, the deployment of more important production units can be intuitively done by connecting several stream current turbines with each others. Alvarez Alvarez et al. [30] suggest a concept of hydrokinetic smart grid (KSG) powered by hydrokinetic micro turbines arranged on line. A full description of each module (mechanical conception, hydraulic power feature, electrical power and control strategies) is included, and the functionality and economic feasibility of the system are illustrated in the case of an installation in Spain. The elemental layout in row of the turbines will be certainly limited in number in the case of river hydrokinetic power, as a result of the narrow topology of some river beds, but the creation of hydrokinetic turbine grid remains the more apparent solution to increase the energy production for a given location.

\section{Conclusions and Discussion}

A synthesis on river or estuarine current power operation has been presented in an autocomplete approach of the scientific literature about this specific sector, whose rise in recent years is undeniable. This report has been motivated by the observation of a lack of paper dealing with the marine/ocean current and the river/estuarine current power distinctly, and a willingness to provide a contribution.

After a brief historic contextualization of the hydrokinetic energy exploitation, an academic analysis on the river/estuarine domain from a quantitative, a thematic and a geographic point of view was realized from two research paper reference resources, in the 2010-2018 period. Globally, the marine and river current power are treated unconcernedly, with a primary interest on the mechanical converter study and the location energy potential estimation.

Following the identification of the world regions where the electrical coverage is unequal, a qualitative analysis of the hydrokinetic power operation potential has been made, allowing firstly finding the area of interest near-shore for marine current power exploitation. Then with the European example, it has been highlighted that countries with river current power potential are more plentiful, on the basis of rainfalls and river drop on their territory. This approach, as applicable to others world regions however, is impacted by the electric energy produced by hydro-power with dams, but the hydrokinetic production potential could be approximated by the production of the run-of-river low-power stations.

From an industrial point of view, the development of the stream current power sector continues globally, despite some project standbys and dropouts. It has been underscored that the undertaken projects can be classified mainly into two categories following the planned nominal power of the production unit, and that high installed capacity projects (in the range of MW) are intended to improve the energy mix at the regional or national scale, unlike the more modest capacity projects which tend to ensure the isolated location electrification or enhance the energy deletion of areas. In terms of operation environment, the first project category is thus more focused on marine current power operation, while the second is more adapted to the river environment, promoting a proximity with consumers. Furthermore, a market study on stream current power confirms the river current power 
growth, with a majority part of patented hydrokinetic technologies dedicated to this environment at worldwide scale. In any case, the actual development of technologies without traditional turbine will help with the exploitation of less energetic locations and rivers and so increase the market of stream current power technologies once they have become commercially sustainable.

Yet this hypothetical growth is slowed down by quite a few factors that, for the most part, are common to ocean and river operation environments:

- A lack of visibility concerning the technically exploitable energy potential, which is also impacted by existing human exploitations;

- A lack of potential or real electric consumption data of locations for the energy need estimation, and/or measure campaigns which are not always public;

- Especially in river and estuarine current power sector, a technological maturity not achieved yet, due to the technology diversity considered by the different industrialists;

- The debris presence in water which can damage the installed turbines, although avoidance solutions exist;

- The environmental impacts associated with the hydrokinetic energy extraction by mechanical converters and the bio-fouling phenomenon, much more severe in marine environment than in freshwater;

- From an economical point of view: A high LCOE of the stream current energy compared to others energy technologies as a result of its innovative feature, difficulties to predict the long-term cost reduction and a lack of investment impacting the future commercialization of hydrokinetic power technologies.

The separate impacts of these factors on the marine and river current power domains, as well as the recommendations and solutions to bring, provide notice that the river/estuarine current power sector seems more sustainable than its marine counterpart.

For this reason, a non-exhaustive synthesis table providing more information on manufacturers developing hydrokinetic systems for river/estuarine environment has been presented. The given information, retrievable online from industrialist websites, shows that a limited number of companies seems to have moved from the commercial stage for a production unit with a hydrokinetic device.

Finally, some technological development acceleration prospects have been defined through recommendations to mitigate the associated constraints, with the deployment of more important production unit composed of several hydrokinetic converters, and with hybrid system conception ensuring an electricity production complementary by exploiting several renewable energies. These two solutions raise an issue of managing a multi-source power generation, and particularly in case of isolated location, of managing micro-grids.

The technical considerations of hydrokinetic devices, such as mechanical structure choice, material and shape of the mechanical converter, or the components and the electromechanical conversion chain topology, have willingly not been detailed in this state-of-art, that is generalist, paper. The bibliography on which this report is articulated is not meant to be exhaustive on the subject of the stream current power domain.

Funding: This research received no external funding.

Author Contributions: J.F. carried out the state of the art review and analyzed the main data; Y.A., G.F., M.B., and N.R. supervised the whole research procedure.

Acknowledgments: This work is supported by Guinard Energies. We also thank all manufacturers for their image use permission.

Conflicts of Interest: The authors declare no conflict of interest. 


\section{References}

1. Paillard, M.; IFREMER. Ces énergies venues de la mer...l'émergence d'une nouvelle filière industrielle. Entretiens Jacques Cartier-ENSE3-Grenoble-20/21 Novembre 2012; Hydro21, IFREMER Conference, 2012. Available online: http://www.hydro21.org/colloque2012/presentations/Michel_Paillard_Hydro2012Grenoble.pdf (accessed on 25 May 2019).

2. Estimate of Global Potential Tidal Resources. Available online: https://marineenergy.biz/2015/02/17/ estimate-of-global-potential-tidal-resources / (accessed on 19 July 2019).

3. IRENA. Renewable Energy Statistics 2018; International Renewable Energy Agency (IRENA): Abu Dhabi, UAE, 2018; p. 362.

4. Els, R.H.V.; Junior, A.C.P.B. The Brazilian Experience with Hydrokinetic Turbines. Energy Procedia 2015, 75, 259-264. doi:10.1016/j.egypro.2015.07.328. [CrossRef]

5. REN21. Renewables 2018 Global Status Report; Technical Report; REN21 Secretariat: Paris, France, 2018; Available online: http:/ / www.ren21.net/gsr-2018/ (accessed on 19 July 2019).

6. Vermaak, H.J.; Kusakana, K.; Koko, S.P. Status of micro-hydrokinetic river technology in rural applications: A review of literature. Renew. Sustain. Energy Rev. 2014, 29, 625-633. doi:10.1016/j.rser.2013.08.066. [CrossRef]

7. Silva, P.A.S.F.; De Oliveira, T.F.; Brasil Junior, A.C.; Vaz, J.R. Numerical study of wake characteristics in a horizontal-axis hydrokinetic turbine. An. Acad. Bras. Cienc. 2016, 88, 2441-2456. doi:10.1590/0001-3765201620150652. [CrossRef] [PubMed]

8. Yuce, M.I.; Muratoglu, A. Hydrokinetic energy conversion systems: A technology status review. Renew. Sustain. Energy Rev. 2015, 43, 72-82, doi:10.1016/j.rser.2014.10.037. [CrossRef]

9. Segura, E.; Morales, R.; Somolinos, J.A. A strategic analysis of tidal current energy conversion systems in the European Union. Appl. Energy 2018, 212, 527-551, doi:10.1016/j.apenergy.2017.12.045. [CrossRef]

10. Yan, X.; Ariaratnam, S.T.; Dong, S.; Zeng, C. Horizontal directional drilling: State-of-the-art review of theory and applications. Tunn. Undergr. Space Technol. 2018, 72, 162-173. doi:10.1016/j.tust.2017.10.005. [CrossRef]

11. Hemer, M.A.; Manasseh, R.; McInnes, K.L.; Penesis, I.; Pitman, T. Perspectives on a way forward for ocean renewable energy in Australia. Renew. Energy 2018, 127, 733-745. doi:10.1016/j.renene.2018.05.036. [CrossRef]

12. Sustainable Development Goal 7. Available online: https://www.iea.org/sdg/electricity/ (accessed on 19 July 2019).

13. Scientific Visualization Studio: TOPEX/Poseidon Images. Available online: https://svs.gsfc.nasa.gov/ stories/topex/tides.html (accessed on 19 July 2019).

14. Aqua-RET E-learning Tool: Resource Maps. Available online: https:/ / www.aquaret.com (accessed on 19 July 2019).

15. Amoo, L.M. Techno-economic assessment of energy production potential from tidal streams in Nigeria. Int. J. Energy Environ. Eng. 2018, 9, 81-98. doi:10.1007/s40095-017-0256-2. [CrossRef]

16. Wagner, B.; Hauer, C.; Schoder, A.; Habersack, H. A review of hydropower in Austria: Past, present and future development. Renew. Sustain. Energy Rev. 2015, 50, 304-314. doi:10.1016/j.rser.2015.04.169. [CrossRef]

17. Chen, H.; Tang, T.; Ait-Ahmed, N.; Benbouzid, M.E.H.; Machmoum, M.; Zaim, M.E.H. Attraction, Challenge and Current Status of Marine Current Energy. IEEE Access 2018, 6, 12665-12685. doi:10.1109/ ACCESS.2018.2795708. [CrossRef]

18. Magagna, D.; Margheritini, L.; Alessi, A.; Bannon, E.; Boelman, E.; Bould, D.; Coy, V.; De marchi, E.; Frigaard, P.; Soares, C.G.; et al. Workshop on Identification of Future Emerging Technologies in The Ocean Energy Sector-27th March 2018; Technical Report March; European Commission: Ispra, Italy, 2018. doi:10.2760/23207. [CrossRef]

19. SEENEOH. Etude de Marché de L'hydrolien-Synthèse Partielle; Technical Report; SEENEOH: Bordeaux, France, 2017.

20. Brooks, D.A. The hydrokinetic power resource in a tidal estuary: The Kennebec River of the central Maine coast. Renew. Energy 2011, 36, 1492-1501. doi:10.1016/j.renene.2010.10.029. [CrossRef]

21. El Tawil, T.; Charpentier, J.F.; Benbouzid, M. Tidal energy site characterization for marine turbine optimal installation: Case of the Ouessant Island in France. Int. J. Mar. Energy 2017, 18, 57-64. doi:10.1016/j.ijome.2017.03.004. [CrossRef] 
22. Murray, D.B.; Gallagher, P.; Duffy, B.; McCormack, V. Energy storage solutions for offshore wave and tidal energy prototypes. In Proceedings of the 2017 Twelfth International Conference on Ecological Vehicles and Renewable Energies (EVER 2017), Monte Carlo, Monaco, 11-13 April 2017. doi:10.1109/EVER.2017.7935944. [CrossRef]

23. Ben Elghali, S.; Outbib, R.; Benbouzid, M. Selecting and optimal sizing of hybridized energy storage systems for tidal energy integration into power grid. J. Mod. Power Syst. Clean Energy 2019, 7, 113-122. doi:10.1007/s40565-018-0442-0. [CrossRef]

24. Tyler, R. River Debris: Causes, Impacts, and Mitigation Techniques; Alaska Center for Energy and Power: Fairbanks, Alaska, 2011; Available online: https://www. google.com.hk/url?sa=t\&rct=j\&q=\&esrc=s\&source=web\&cd=1\&cad=rja\&uact=8\&ved= 2ahUKEwizs8eNuKLlAhXBM94KHVvqDCQQFjAAegQIAxAC\&url=http\%3A\%2F\%2Facep.uaf.edu\% 2Fmedia\%2F89819\%2F2011_4_13_AHERC-River-Debris-Report.pdf\&usg=AOvVaw22wHU_CV2kLjFs_ aFXkAUP (accessed on 19 July 2019).

25. Nash, S.; Phoenix, A. A review of the current understanding of the hydro-environmental impacts of energy removal by tidal turbines. Renew. Sustain. Energy Rev. 2017, 80, 648-662. doi:10.1016/j.rser.2017.05.289. [CrossRef]

26. Titah-Benbouzid, H.; Benbouzid, M. Marine Renewable Energy Converters Biofouling: A Critical Review on Impacts and Prevention. In Proceedings of the 11th European Wave and Tidal Energy Conference, At Nantes, France, 6-11 September 2015; pp. 1-8.

27. Roy, A.; Auger, F.; Dupriez-Robin, F.; Bourguet, S.; Tran, Q.T. Electrical power supply of remote maritime areas: A review of hybrid systems based on marine renewable energies. Energies 2018, 11, 1904. doi:10.3390/en11071904. [CrossRef]

28. Tekobon, J. Multi-Physical System of Simulation for the Study of Energy Production Based on Offshore Wind and Tidal Power Hybrid System. Ph.D. Thesis, Université du Havre, Le Havre, France, 2016.

29. Zia, M.F.; Elbouchikhi, E.; Benbouzid, M. Microgrids energy management systems: A critical review on methods, solutions, and prospects. Appl. Energy 2018, 222, 1033-1055. doi:10.1016/j.apenergy.2018.04.103. [CrossRef]

30. Alvarez Alvarez, E.; Rico-Secades, M.; Corominas, E.L.; Huerta-Medina, N.; Soler Guitart, J. Design and control strategies for a modular hydroKinetic smart grid. Int. J. Electr. Power Energy Syst. 2018, 95, 137-145. doi:10.1016/j.ijepes.2017.08.019. [CrossRef]

(C) 2019 by the authors. Licensee MDPI, Basel, Switzerland. This article is an open access article distributed under the terms and conditions of the Creative Commons Attribution (CC BY) license (http:/ / creativecommons.org/licenses/by/4.0/). 